\title{
Waveguides for Mid-Infrared Group IV Photonics
}

\author{
G. Z. Mashanovich, W. R. Headley, M. M. Milosevic, N. Owens, E. J. Teo, B. Q. Xiong, \\ P. Y. Yang, M. Nedeljkovic, J. Anguita, I. Marko, and Y. Hu
}

\begin{abstract}
In this paper we present preliminary work on group IV photonic waveguides that may be suitable for mid-infrared wavelengths. Fabrication and experimental results for two waveguide structures are given.
\end{abstract}

Index Terms- silicon-on-insulator, silicon-on-sapphire, germanium, porous silicon, mid-infrared photonics

\section{INTRODUCTION}

$\mathrm{S}_{\mathrm{r}}^{\mathrm{n}}$ ILICON photonics has been an extremely buoyant field recently with a number of breakthroughs reported and a very intensive work being performed in areas such as optical interconnects, sensors and fibre to the home (FTTH) applications. Much of the current focus in silicon photonics is in the telecom wavelength range. However, silicon is relatively low-loss from 1.2 to $8 \mu \mathrm{m}$ and from 24 to $100 \mu \mathrm{m}$ [1], and therefore silicon photonic circuits can be used in mid- and farinfrared wavelength ranges. The mid-infrared (MIR) spectral region is particularly interesting, as the practical realization of optoelectronic devices operating in this wavelength range offers potential applications in a wide variety of areas, including optical sensing and environmental monitoring, freespace communications, biomedical engineering, thermal imaging, and IR countermeasures [2], [3]. Furthermore, the free-carrier plasma dispersion effect is much stronger at wavelengths longer than $1.55 \mu \mathrm{m}$ [4], and two photon absorption is significantly reduced at MIR wavelengths beyond the telecommunication band [5]. Additionally, more robust optical fibres are now available for this wavelength range (e.g. [6]). Finally, the larger dimensions of MIR devices mean that the dimensional tolerances will be more relaxed compared to those in the near-infrared (NIR), thus simplifying fabrication [7]. However, the advantages of this wavelength

Manuscript received 8 June 2010. This work was supported by the Royal Society under 'Mid-infrared silicon photonics' Research Fellowship and in part by EPSRC under 'UK Silicon Photonics' grant.

G. Mashanovich, W. Headley, M. Milosevic, N. Owens, M. Nedeljkovic, J. Anguita, I. Marko, and Y. Hu are with the Advanced Technology Institute, University of Surrey, Guildford, GU2 7XH, UK (corresponding author: +44 1483 686123; fax: +44 1483 689404; e-mail: g.mashanovich@surrey.ac.uk).

E. J. Teo and B. Q. Xiong are with the Centre for Ion Beam Applications (CIBA), Department of Physics, 2 Science Drive 3, National University of Singapore, 117542, Singapore. range have not been fully exploited owing to the limitations in current technology.

The fundamental challenge for group IV photonics in this wavelength range is the fact that the most popular material platform in the NIR range, that of silicon-on-insulator, cannot be used in most parts of the MIR, due to high material losses of $\mathrm{SiO}_{2}$ in the 2.6-2.9 $\mu \mathrm{m}$ range and beyond $3.6 \mu \mathrm{m}$ [8], [9]. Therefore, other waveguide structures must be developed. Soref et al. proposed several waveguide structures suitable for mid- and long-IR spectral regions [10]: Si rib-membrane waveguides, $\mathrm{Si}$ on $\mathrm{Si}_{3} \mathrm{~N}_{4}$ (SON), $\mathrm{Si}$ on sapphire (SOS) [11], Ge-on-Si, Ge on SOI or GeSn-on-Si strip and slot waveguides, hollow waveguides with Bragg or anti-resonant cladding [12], [13], and silicon on porous silicon waveguides [14], [15]. Freestanding waveguides fabricated by the proton beam writing technique are also candidates for MIR group IV photonics [16]. As waveguide dimensions scale with the wavelength, in order to reduce the dimensions and facilitate CMOS compatibility of MIR devices, plasmonic waveguides and plasmonic waveguided components may prove to be a suitable solution [10]. It is expected that the plasmonic propagation loss decreases significantly as the wavelength of operation is increased into the MIR and far-IR [17].

Research in MIR group IV photonics is gathering pace and there have been several recent results reported in the field: Raman amplification at the wavelength of $3.39 \mu \mathrm{m}$ has been demonstrated [18], a spectrally selective mid-IR PbTe photodetector (around $3.7 \mu \mathrm{m}$ ) has been monolithically integrated on a silicon platform [19], and non-linear effects at shorter MIR wavelengths have been investigated [20]-[23].

Here, we report preliminary results for two waveguide structures, silicon-on-insulator (SOI) and $\mathrm{Si}$ on porous $\mathrm{Si}$ (SiPSi). SOI waveguides could be used around $3 \mu \mathrm{m}$ as oxide is low loss in that wavelength range, whereas $\mathrm{Si}$ on porous $\mathrm{Si}$ could potentially be used at longer wavelengths.

\section{SILICON WAVEGUIDES FOR MIR PHOTONICS}

\section{A. Silicon-on-insulator}

We have previously reported design rules for single mode and polarization independent SOI rib waveguides at the wavelength of $3.39 \mu \mathrm{m}$ [9]. We have used those design rules to fabricate SOI rib waveguides with $\mathrm{H}=2 \mu \mathrm{m}$ by using standard 
lithography and RIE etching. The propagation loss was measured by using a setup that comprised a HeNe $3.39 \mu \mathrm{m}$ laser, InSb detector, MIR fibres and optics [6], [24]. The measured propagation losses were in the range of $2-3 \mathrm{~dB} / \mathrm{cm}$. The buried oxide thickness was $1 \mu \mathrm{m}$ and lower propagation losses are expected for waveguides with thicker oxide layer.

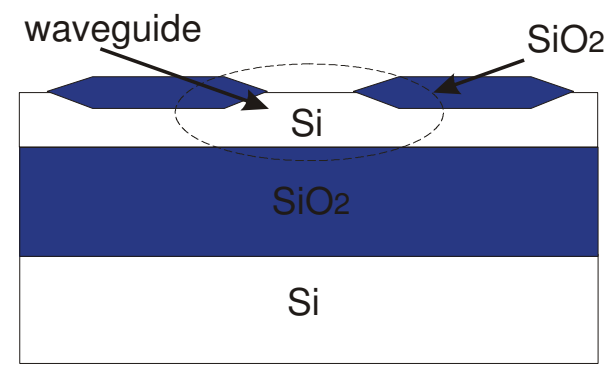

Fig. 1. Schematic of LOCOS waveguide

Another structure that is interesting for this wavelength range is the LOCOS waveguide [25], that we have previously measured at telecoms wavelengths, and are now reported here for MIR wavelengths for the first time. The starting material was a p-type wafer with a $1500 \mathrm{~nm}$ thick silicon overlayer, and a $2.8 \mu \mathrm{m}$ buried oxide layer. The wafer was thinned using thermal oxidation and subsequently etched in buffered HF to reduce the overlayer thickness to around $650 \mathrm{~nm}$. A $40 \mathrm{~nm}$ $\mathrm{SiO}_{2}$ layer and a $\mathrm{Si}_{3} \mathrm{~N}_{4}$ masking layer of $80 \mathrm{~nm}$ were deposited by Chemical Vapour Deposition (CVD). Trenches in the $\mathrm{Si}_{3} \mathrm{~N}_{4}$ layer were then defined by photolithography and plasma etched. The structure was subsequently wet-oxidized to produce a $410 \mathrm{~nm}$ thick $\mathrm{SiO}_{2}$ layer in the unmasked trench areas. Finally, the $\mathrm{Si}_{3} \mathrm{~N}_{4}$ layer was removed to leave an optical waveguide between the oxidized trenches (Fig. 1). The fabrication process results in a reduced sidewall roughness and smaller sidewall angle $\left(22-27^{\circ}\right)$. The propagation loss of 770 $\mathrm{nm}$ high waveguides at the wavelength of $3.39 \mu \mathrm{m}$ was around $1.4 \mathrm{~dB} / \mathrm{cm}$. Further investigation is needed to establish the propagation loss dependence on the waveguide width, but these losses are extremely promising for MIR applications.

\section{B. Silicon on porous Silicon}

By replacing the oxide with a different cladding, we can potentially obtain waveguides that guide longer MIR wavelengths. Such a cladding can be air or porous silicon. We have fabricated silicon on porous silicon waveguides by using the following fabrication process.

First, a UV patterned photoresist (PR) is deposited onto a bulk $p$-type silicon sample of $0.7 \Omega$.cm resistivity (Fig. 2a). Ion irradiation using $250 \mathrm{keV}$ protons is then performed with a fluence of $5 \times 10^{13} / \mathrm{cm}^{2}$. After irradiation and mask removal, the sample is electrochemically etched in a solution of HF:water:ethanol with a ratio of 1:1:2. To obtain the surface relief strip structure, we have performed a two-step etching process. First, the sample is electrochemically etched in $12 \%$
HF with a current density of $100 \mathrm{~mA} / \mathrm{cm}^{2}$ until the end of the ion range is reached. Here, the ion irradiation acts to increase the resistivity of silicon, deflecting the migrating holes from the irradiated regions (see arrows in Fig. 2b). This selectively prevents porous silicon (PS) from forming in the irradiated regions [15]. The sample is then dipped in dilute potassium hydroxide $(\mathrm{KOH})$ solution to remove the remaining PS formed in the un-irradiated regions (Fig. 2c). A second etching step is carried out at $24 \% \mathrm{HF}$ with a current density of $40 \mathrm{~mA} / \mathrm{cm}^{2}$ in order to undercut the structure completely (Fig. 2d). The crosssectional scanning electron microscopy (SEM) image in Fig. 3 reveals a silicon-on-porous silicon waveguide, with a $5 \times 2.5$ $\mu \mathrm{m}$ rectangular Si core that is optically confined by a $5 \mu \mathrm{m}$ thick bottom PS cladding (Fig. 3). Owing to the isotropic etching process, a cusp is formed at the point where the waveguide is detached from the Si substrate.

(a)

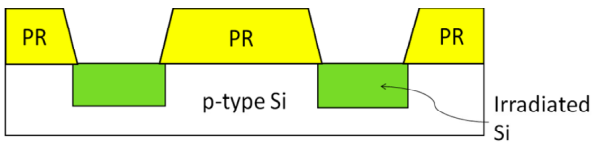

(b)

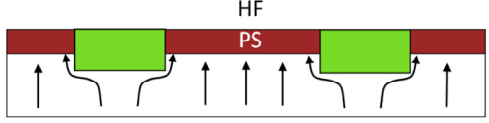

(c)

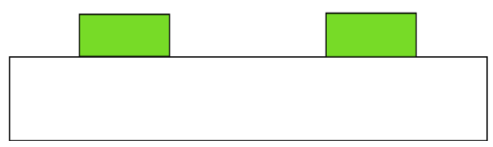

(d)

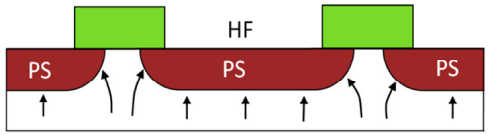

Fig. 2. Schematic diagram of the silicon on porous silicon waveguide fabrication process

The sample is then annealed in an argon atmosphere at 500 ${ }^{\circ} \mathrm{C}$ for 1 hour to remove any residual ion defects. The refractive index of the annealed PS is found to be about 1.4 from fitting the reflectance spectra using the Bruggeman formula [26].

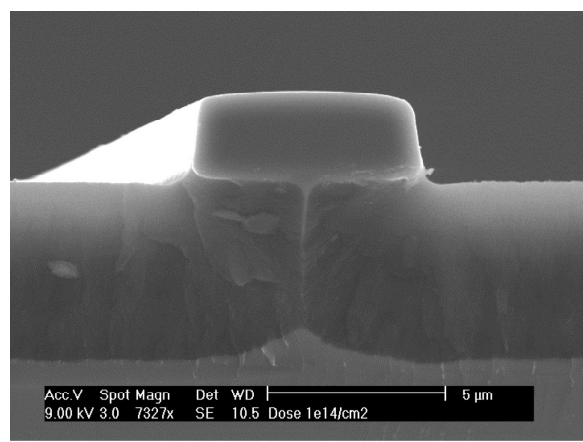

Fig. 3. Cross section of the silicon-on-porous silicon waveguide 
The propagation loss is estimated by using the cut-back method [27]. At the wavelength of $3.39 \mu \mathrm{m}$ (Fig. 4), the propagation loss was around $5 \mathrm{~dB} / \mathrm{cm}$. We believe that this figure can be significantly reduced, to values around $1 \mathrm{~dB} / \mathrm{cm}$, by oxidation of the samples, and hence reduction of the surface roughness, similar to the work reported in [15]. The SiPSi waveguides will be tested at different MIR wavelengths to investigate their viability for longer wavelength applications.

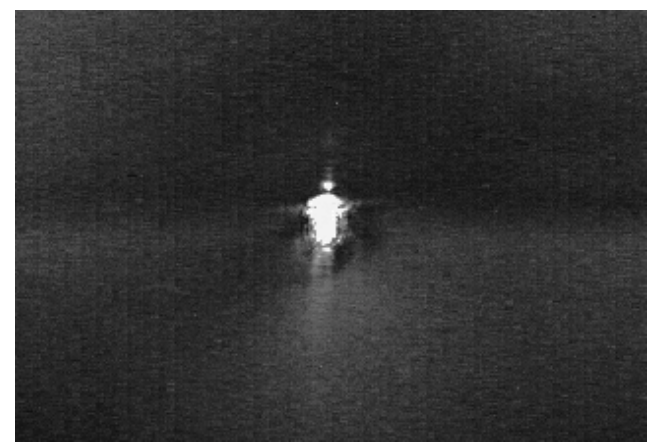

Fig. 4. Output MIR light imaged at Si on porous Si waveguide facet

\section{CONCLUSION}

In this paper, preliminary work on group IV waveguides that can find application in the mid-infrared wavelength range is presented. Fabrication of two waveguide structures and propagation loss measurements at the wavelength of $3.39 \mu \mathrm{m}$, have been carried out. The propagation losses are relatively high and further work is underway to reduce those figures. It is interesting to note that the waveguides fabricated during the early 1990's for telecommunication device wavelengths also reported high propagation losses initially, which have been reduced significantly in the last several years. If MIR devices can make similar progress, then we should in the near future expect to see some rather remarkable advances in MIR optical components and their use in a host of applications offered by the MIR spectral range.

\section{REFERENCES}

[1] G. J. Hawkins, "Spectral characteristics of infrared optical materials and filters", Ph.D. dissertation, University of Reading, 1998.

[2] A. Krier, (Ed.), Mid-Infrared Semiconductor Optoelectronics. London: Springer-Verlag, 2006.

[3] L. Labadie and O. Wallner, "Mid-infrared guided optics: a perspective for astronomical instruments," Optics Express, vol. 17, pp.1947-1962, 2009.

[4] R. A. Soref, S. J. Emelett, and W. R. Buchwald, "Silicon waveguided components for the long-wave infrared region," J. Opt. A, vol. 8, pp. 840-848, 2006.

[5] X. Liu, J. B. Driscoll, J. I. Dadap, R. M. Osgood, Y. A. Vlasov and M. J. Green, "Mid-infrared pulse dynamics in Si nanophotonic wires near the two-photon absorption edge", in Proc. CLEO 2009, Baltimore, MD, USA, 31 May - 5 June 2009, paper CFR5.

[6] www.irphotonics.com

[7] G. T. Reed (ed.), Silicon Photonics: The State of the Art. Chichester: Wiley and Sons, 2008

[8] E. D. Palik, Handbook of Optical Constants of Solids, Vol. 1, London: Academic, London, 1985 .
[9] M. M. Milosevic, P. S. Matavulj, P. Y. Yang, A. Bagolini and G. Z. Mashanovich, "Rib waveguides for mid-infrared silicon photonics," $J$. Opt. Soc. Am. B, vol. 26, pp.1760-1766, 2009.

[10] R. Soref, "Towards silicon-based longwave integrated optoelectronics (LIO)", Proc. SPIE, vol. 6898, 689809-1, 2008.

[11] T. Baehr-Jones, A. Spott, R. Ilic, A. Spott, B. Penkov, W. Asher, and M. Hochberg, "Silicon-on-sapphire integrated waveguides for the midinfrared," Opt. Express, vol. 18, pp. 12127-12135, 24 May 2010.

[12] G. Z. Mashanovich, M. Milosevic, P. Matavulj, B. Timotijevic, S. Stankovic, P. Y. Yang, E. J. Teo, M. B. H. Breese, A. A. Bettiol and G. T. Reed, "Silicon photonic waveguides for different wavelength regions," Semiconductor Sci. Technol., vol. 23, 064002, 2008.

[13] R. M. Jenkins, B. J. Perrett, M. E. McNie, E. D. Finlayson, R. R. Davies, J. Banerji and A. R. Davies, "Hollow optical waveguide devices and systems", in Proc. SPIE Europe Optics/Photonics in Security and Defence, vol. 7113, 71130E, 2008.

[14] E. J. Teo, A. A. Bettiol, M. B. H. Breese, P. Y. Yang, G. Z. Mashanovich, W. R. Headley, G. T. Reed and D. J. Blackwood, "Threedimensional fabrication of silicon waveguides with porous silicon cladding," Opt. Express, vol. 16, pp. 573-578, 2008.

[15] E. J. Teo, A. A. Bettiol, P. Yang, M. B. H. Breese, B. Q. Xiong, G. Z. Mashanovich, W. R. Headley and G. T. Reed, "Fabrication of low loss silicon-on-oxidized porous silicon strip waveguides using focused proton beam irradiation," Opt. Lett., vol. 34, pp. 659-661, 2009.

[16] P. Y. Yang, G. Z. Mashanovich, I. Gomez-Morilla, W. R. Headley, G. T. Reed, E. J. Teo, D. J. Blackwood, M. B. H. Breese and A. A. Bettiol, "Free standing waveguides in silicon," Appl. Phys. Lett., vol. 90, 241109, 2007.

[17] R. Soref, R. E. Peale and W. Buchwald, "Longwave plasmonics on doped silicon and silicides," Opt. Express, vol. 16, pp. 6505-6514, 2009.

[18] V. Raghunathan, D. Borlaug, R. R. Rice and B. Jalali, "Demonstration of a mid-infrared silicon Raman amplifier", Opt. Express, vol. 15, pp. $14355-14362,2007$.

[19] J. Wang, J. Hu, X. Sun, P. Becla, A. M. Agarwal and L. C. Kimerling, "Spectral Selective Mid-infrared Detector on a Silicon Platform," in Proc. IEEE Group IV Photonics conference, 9-11 September 2009, San Francisco, USA, paper FB7.

[20] X. Liu, R. M. Osgood, Y. A. Vlasov and W. M. J. Green, "Broadband mid-infrared parametric amplification, net off-chip gain, and cascaded four-wave mixing in silicon photonic wires", in Proc. IEEE Group IV Photonics conference, 9-11 September 2009, San Francisco, USA, paper PD1.3, 2009.

[21] J. S. Park, S. Zlatanovic, S. Moro, J. M. Chavez-Boggio, I. B. Divliansky, S. Kookherjea, and S. Radic, "Mid-infrared four-wave mixing in silicon waveguides using telecom-compatible light source," presented at Frontiers in Optics (FiO) 2009, San Jose, CA, 11-15 October 2009, Postdeadline paper PDPB3 9/2009.

[22] X. Liu, R. M. Osgood, Y. A. Vlasov, and W. M. J. Green, "Mid-infrared optical parametric amplifier using silicon nanophotonic waveguides," Nature Photonics (advanced online publication) May 2010.

[23] S. Zlatanovic, J. S. Park, S. Moro, J. M. Chavez-Boggio, I. V. Divliansky, N. Alic, S. Mookherjea, and S. Radic, "Mid-infrared wavelength conversion in silicon waveguides using ultracompact telecom-band-derived pump source," Nature Photonics (advanced online publication) May 2010.

[24] www.cascade-technologies.com

[25] F. Y. Gardes, G. T. Reed, A. P. Knights, G. Mashanovich, P. E. Jessop, L. Rowe, S. McFaul, D. Bruce, and N. G. Tarr, "Sub-micron optical waveguides for silicon photonics formed via Local Oxidation of Silicon (LOCOS),“ Photonics West 2008, San Jose, CA, USA, January 2008, paper 6898-23.

[26] D. E. Aspnes, "Optical properties of thin films," Thin Solid Films, vol. 89 , pp. 249-262, 1982

[27] G. T. Reed and A. P. Knights, Silicon Photonics: An Introduction. Chichester: Wiley, 2004. 